\title{
Echografie bij schouderpijn: doen of niet?
}

Samenvatting

Ottenheijm RPG. Echografie bij schouderpijn: doen of niet? Huisarts Wet 2016;59(12):551-3.

De prognose van schouderpijn is ongunstig. De NHG-Standaard Schouderklachten adviseert echografie te overwegen bij patiënten die ondanks behandeling pijn blijven houden. In deze beschouwing beschrijf ik de plaats van echografie in het diagnostisch proces, met als doel het verbeteren van de prognose. Huisartsen stellen bij voorkeur een specifieke diagnose en hebben verschillende visies op de plaats van echografie: aanvragen tijdens de beginfase van een episode, bij chronische klachten of helemaal niet. Echografie is een accuraat instrument voor het stellen van specifieke diagnoses. Bij de grote meerderheid van patiënten maakt echografie het mogelijk om een specifieke diagnose te stellen. Bij patiënten met een eerste episode lijkt behandeling op basis van een echografische diagnose na één jaar echter niet te leiden tot een betere prognose. Deze bevinding ondersteunt het NHG-advies om in de beginfase van een episode geen echografie aan te vragen. Huisartsen kunnen de NHG-Standaard blijven volgen: overweeg alleen dan een echografie wanneer patiënten ondanks behandeling pijn blijven houden.

\section{INLEIDING}

Schouderpijn is een veelvoorkomende klacht in de huisartsenpraktijk en de prognose is ongunstig: 40\% van de patiënten is na een jaar nog niet genezen. Meestal is er sprake van een subacromiale aandoening. ${ }^{1}$ De NHG-Standaard Schouderklachten adviseert om schouderklachten in te delen op basis van pijn en de bevindingen van het lichamelijk onderzoek. De Standaard ontraadt het om een specifieke diagnose te stellen, een classificatie die berust op onderliggende pathologische anatomische aandoeningen. Met de gegevens uit de anamnese en het lichamelijk onderzoek kan je immers doorgaans niet precies vaststellen wat de oorzaak van de schouderpijn is of welke structuur is aangedaan. Wel geven de anamnese en het lichamelijk onderzoek een indicatie voor de lokalisatie: een afwijking in het subacromiale gebied of glenohumerale gewricht. Daarom luidt het advies om een stapsgewijze behandeling te starten, die is gericht op de pijn en/of het beperken of voorkómen van disfunctioneren. ${ }^{1}$

Bij deze aanpak is de behandeling dus niet gericht op een specifieke diagnose. Verwijzing voor aanvullende beeldvormende diagnostiek om een specifieke oorzaak aan te tonen of uit te sluiten, zoals echografie, is pas aan te raden bij patiënten die ondanks behandeling klachten blijven houden. ${ }^{1}$ Huisartsen vragen echter geregeld een echografie van de schouder aan. In het adherentiegebied van een Limburgs ziekenhuis vragen huisartsen jaarlijks ongeveer tweeduizend keer een echografie van de schouder aan. ${ }^{2}$ Het diagnostisch proces zoals de NHG-Standaard dat beschrijft lijkt eenvoudig, maar uit de prognose blijkt dat het huidige beleid niet optimaal is. Be- langrijke vragen zijn: hoe ervaart de huisarts dit diagnostisch proces en kunnen we de prognose verbeteren door te starten met een behandeling die zich richt op een echografische diagnose bij patiënten met een eerste episode van schouderpijn (duur minder dan drie maanden)?

\section{AANBEVELINGEN VOOR DE HUISARTS}

Aanvullende diagnostiek is alleen van waarde als we daarmee de behandeling en dus de prognose kunnen verbeteren. De NHG-Standaard beveelt echografie niet aan tijdens de beginfase van een eerste episode van schouderpijn, waarbij de huisarts een subacromiale aandoening vermoedt. Uit ons onderzoek blijkt dat de prognose niet lijkt te verbeteren wanneer de behandeling is gebaseerd op een echografische diagnose. Huisartsen kunnen de NHG-Standaard blijven volgen: overweeg een echografie indien patiënten ondanks behandeling pijn blijven houden. ${ }^{1}$ Er is dus nog geen bewijs om hiervan af te wijken. In het kader van een zinnig en zuinig aanvraagbeleid kan dit advies wel worden aangevuld voor patiënten bij wie de huisarts een subacromiale aandoening vermoedt: overweeg een echografie bij een leeftijd $\geq 40$ jaar, omdat bij de meerderheid van deze groep echografisch een subacromiale aandoening is vast te stellen. Daarnaast kan men echografie ook inzetten om patiënten gerust te stellen, zeker wanneer er sprake is van ongunstige prognostische factoren, zoals pijn die al lange tijd bestaat en ernstige pijn.

\section{DE UITGEVOERDE ONDERZOEKEN}

Perspectief op het diagnostisch proces

Uit semigestructureerde interviews met achttien doelgericht gekozen huisartsen blijkt dat huisartsen gebruikmaken van

\section{De kern}

- Bij patiënten met schouderpijn luidt het advies geen specifieke diagnose te stellen en de behandeling te richten op pijn en beperkingen. De prognose is ongunstig: $40 \%$ is na één jaar niet genezen.

- De prognose lijkt niet te verbeteren bij patiënten met een eerste episode van subacromiale schouderpijn (duur minder dan drie maanden) indien men start met een behandeling die gebaseerd is op een echografische diagnose.

- Huisartsen kunnen de NHG-Standaard blijven volgen: overweeg alleen een echografie wanneer patiënten ondanks behandeling pijn blijven houden.

Universiteit Maastricht, Vakgroep Huisartsgeneeskunde, postbus 616, 620o MD Maastricht: dr. R.P.G. Ottenheijm, kaderhuisarts bewegingsapparaat • Correspondentie: ramon.ottenheijm@ maastrichtuniversity.nl • Mogelijke belangenverstrengeling: niets aangegeven.

Deze beschouwing is gebaseerd op het proefschrift: Ottenheijm RPG. Ultrasound imaging to tailor treatment of shoulder pain in general practice. Maastricht: Universiteit Maastricht, 2015. 
een variëteit aan diagnostische classificaties en dat, ondanks aanbevelingen in de NHG-Standaard, ze toch graag een specifieke diagnose stellen. ${ }^{3}$ Daarnaast verschillen huisartsen onderling in de gehanteerde strategie om tot een diagnose te komen. Deze verschillen zijn gebaseerd op kennis en persoonlijke ervaring, maar ook op voorkeuren van patiënten. De deelnemende huisartsen vertellen dat het aanvragen van beeldvormende diagnostiek en intercollegiale consultatie of verwijzing kan helpen om meer greep te krijgen op het diagnostisch proces of om de patiënt gerust te stellen. De deelnemende huisartsen verschilden van mening over de plaatsbepaling van echografie. Er zijn huisartsen die echografie aanvragen bij eerste episoden van schouderpijn, terwijl andere dit pas doen bij chronische klachten of vinden dat ze geen toegevoegde waarde heeft.

\section{Diagnostische waarde}

De diagnostische waarde van echografie bij subacromiale aandoeningen was tot dusver alleen onderzocht voor volledige en partiële dikterupturen van de rotator cuff-pezen in patiëntenpopulaties in het ziekenhuis. Van de subacromiale aandoeningen die we vooral in de huisartsenpraktijk verwachten bij een eerste episode van schouderpijn - tendinopathie, tendinitis calcarea en bursitis subacromialis-subdeltoidea - was de diagnostische waarde van echografie nog niet bekend. In een systematische review met meta-analyse hebben we de diagnostische waarde van echografie voor het gehele spectrum van subacromiale aandoeningen onderzocht. ${ }^{4}$ We hebben 23 onderzoeken geïncludeerd, waarvan er geen enkele in de huisartsenpraktijk is uitgevoerd. [Tabel 1] geeft het aantal onderzoeken per aandoening en de sensitiviteit en specificiteit weer. Statische pooling was alleen mogelijk voor volledige en partiële dikterupturen. Deze resultaten laten zien dat echografie geschikt is voor het aantonen (specificiteit) van de subacromiale aandoeningen en dat het uitsluiten ervan (sensitiviteit) minder accuraat is voor tendinopathie en partiële dikterupturen. We moeten de resultaten wel met enige voorzichtigheid interpreteren, omdat het patiëntenpopulaties uit het ziekenhuis betreft.

\footnotetext{
Abstract

Ottenheijm RPG. Ultrasound imaging for shoulder pain: is it necessary? Huisarts Wet 2016;59(12):557-3.

The prognosis of shoulder pain is unfavourable. According to the guidelines of the Dutch College of General Practitioners, ultrasound imaging should be considered if pain is refractory. This review discusses the role of ultrasound in the diagnostic workup, with a view to improving the prognosis. While general practitioners would prefer to establish a specific diagnosis, the role of ultrasound is not unequivocal - is it necessary, or should it be ordered early in the disorder or only if symptoms become chronic? Although ultrasound is accurate for diagnosing specific disorders and allows a diagnosis to be established in most patients, the prognosis of patients with a first episode of shoulder pain treated on the basis of ultrasound findings does not seem to be improved after 1 year. This supports the College's recommendation that ultrasound not be ordered in the early phase of an episode and that it should be considered only in patients with refractory pain.
}

Tabel 1 Diagnostische waarde van echografie voor de subacromiale aandoeningen

\begin{tabular}{|c|c|c|c|}
\hline Aandoening & $\begin{array}{l}\text { Aantal } \\
\text { onderzoeken }\end{array}$ & $\begin{array}{l}\text { Sensitiviteit } \\
(\%)\end{array}$ & $\begin{array}{l}\text { Specificiteit } \\
(\%)\end{array}$ \\
\hline Volledige dikteruptuur & 22 & $95 \%$ & $96^{*}$ \\
\hline Partiële dikteruptuur & 15 & $72^{*}$ & $93^{*}$ \\
\hline Tendinopathie & 2 & $67-93$ & $88-100$ \\
\hline Tendinitis calcarea & 2 & 100 & $85-98$ \\
\hline Bursitis & 3 & $79-81$ & $94-98$ \\
\hline
\end{tabular}

"Statistische pooling

\section{Specifieke diagnoses}

We hebben een prospectief observationeel onderzoek uitgevoerd, waarbij een ervaren radioloog bij 129 patiënten met een leeftijd tussen 18 en $6_{5}$ jaar een gestandaardiseerde echografie

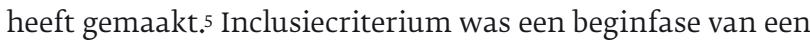
eerste episode van schouderpijn, waarbij de huisarts op basis van de diagnostische classificatie uit de NHG-Standaard tot de conclusie kwam dat er sprake was van een subacromiale aandoening. Bij $81 \%$ van de patiënten kon de radioloog een subacromiale aandoening vaststellen en bij de helft hiervan zag hij minimaal twee aandoeningen. [Tabel 2] geeft de frequentie weer van de gevonden subacromiale aandoeningen. Tendinitis calcarea blijkt met 50\% de meest gevonden specifieke diagnose. Leeftijd $\geq 40$ jaar bleek de belangrijkste voorspeller te zijn voor het hebben van een subacromiale aandoening (oddsratio 14,93, 95\%-BI 5,17-43,14). Meer dan 90\% van de patienten $\geq 40$ jaar had een subacromiale aandoening, terwijl dit percentage bij patiënten jonger dan 40 jaar 39\% was.

\section{Het effect van behandeling op maat}

Bij een volgend onderzoek, een gerandomiseerde klinische trial, ${ }^{6}$ was de onderzoekspopulatie gelijk aan die uit het bovengenoemde prospectieve observationele onderzoek. Alle patiënten kregen een behandeling door hun eigen huisarts; de eerste twee weken met paracetamol of NSAID. Na deze twee weken bleken achttien patiënten genezen te zijn. De overige 111 patiënten hebben we gelijk verdeeld over twee onderzoeksgroepen: behandeling op basis van de echografisch vastgestelde specifieke diagnose (interventiegroep) vergeleken we met behandeling volgens de NHG-Standaard (controlegroep). Ervaren radiologen hebben op een gestandaardiseerde manier echografieën gemaakt. Voor de interventiegroep was een

Tabel 2 Frequentie van echografisch vastgestelde specifieke diagnoses

\begin{tabular}{ll} 
Aandoening & Frequentie (\%) \\
\hline Geen afwijking gevonden & 19 \\
Aandoening aanwezig & 81 \\
Specifieke aandoeningen & \\
- Tendinitis calcarea & 50 \\
- Tendinopathie & 29 \\
- Bursitis & 20 \\
- Partiële dikterupturen & 19 \\
- Volledige dikterupturen & 3 \\
\hline
\end{tabular}


Tabel 3 Eerste behandelstap naar aanleiding van een echografische diagnose

\begin{tabular}{ll} 
Aandoening & Eerste behandelstap \\
\hline Tendinitis calcarea & Corticosteroïdinjectie \\
Tendinopathie & Fysiotherapie \\
Bursitis & Corticosteroïdinjectie \\
Partiële dikterupturen & Fysiotherapie \\
Volledige dikterupturen & Verwijzing orthopedie \\
\hline
\end{tabular}

behandelplan opgesteld [tabel 3]. Voor de primaire uitkomstmaat, genezing na één jaar, laten de resultaten een niet-significant effect zien in het voordeel van de interventiegroep (72,5\% versus 60\%; oddsratio 2,24; 95\%-BI o,72-6,89; $\mathrm{p}=0,16)$. Tevens was er geen verschil in het aantal verwijzingen naar een medisch specialist of fysiotherapeut en het aantal corticosteroïdinjecties. Helaas kunnen we geen definitieve conclusies trekken, omdat er te weinig patiënten waren geïncludeerd.

\section{BESCHOUWINC}

De prognose lijkt niet te verbeteren bij patiënten met een eerste episode van subacromiale schouderpijn (duur minder dan drie maanden) indien de huisarts start met een behandeling op basis van een echografische diagnose. Helaas kunnen we nog geen harde conclusies trekken, omdat er te weinig patienten aan dit onderzoek hebben deelgenomen. Aangezien echografie aanvullende diagnostiek betreft, lijkt het gerechtvaardigd om hier vanaf te zien in de beginfase van een episode en deze zoals de NHG-Standaard adviseert te reserveren voor aanhoudende klachten.

Echografie blijkt een accuraat diagnosticum te zijn voor het stellen van specifieke diagnoses, maar we moeten er wel rekening mee houden dat ze voor het uitsluiten van een tendinopathie en partiële peesruptuur minder betrouwbaar is. Dat komt onder andere doordat de diagnostische criteria voor tendinopathie en partiële rupturen overlappen. We moeten de resultaten wel met enige voorzichtigheid interpreteren, omdat het patiëntenpopulaties uit het ziekenhuis betreft. Bij het merendeel van de patiënten van 40 jaar of ouder met een eerste episode van subacromiale schouderpijn kan de radioloog echografisch een specifieke diagnose stellen. In het kader van zinnig en zuinig aanvragen lijkt het gerechtvaardigd om dit leeftijdscriterium te gebruiken, indien de huisarts echografie overweegt.

Huisartsen vragen geregeld echografie van de schouder aan. $^{2}$ Dit leidt tot specifieke diagnoses. De NHG-Standaard gaat niet in op de diagnostiek, behandeling en prognose van de specifieke diagnoses. Door een gebrek aan kennis kan dit, zoals verondersteld in de NHG-Standaard, leiden tot onnodige verwijzingen. In ons onderzoek bleek er echter geen verschil te zijn in het aantal verwijzingen naar een medisch specialist of fysiotherapeut. Een mogelijke verklaring hiervoor kan zijn dat de deelnemende huisartsen informatie hebben ontvangen over de pathofysiologie en het natuurlijk beloop van de echografisch vastgestelde specifieke diagnose. Bij een herziening van de NHG-Standaard zou men hier aandacht aan kun- nen besteden. Tevens kunnen huisartsen consultatie van een kaderhuisarts bewegingsapparaat overwegen, omdat deze verwijzing naar een medisch specialist kan voorkomen.

Huisartsen blijken een variëteit aan diagnostische classificaties te gebruiken en, hoewel de NHG-Standaard dat niet adviseert, een voorkeur te hebben voor specifieke diagnoses. De vraagt dringt zich op waarom ze deze voorkeur hebben, zeker nu blijkt dat de prognose niet lijkt te verbeteren als ze in de beginfase van een episode echografisch een specifieke diagnose stellen. De NHG-Standaard hanteert een classificatie op basis van pijn en beperkingen. Mogelijk vinden huisartsen het moeilijk om deze indeling te gebruiken. Een van de strategieën die huisartsen hanteren bij het omgaan met diagnostische onzekerheid, is het aanvragen van echografie, zowel in de beginfase als bij chronische klachten. Nu blijkt dat de prognose niet verbetert met echografie in de beginfase, kunnen huisartsen dat met hun patiënten bespreken. Voor een goede onderlinge communicatie tussen huisarts, fysiotherapeut en medisch specialist is een eenduidige classificatie aan te bevelen. Zowel de Nederlandse Orthopaedische Vereniging als het Koninklijk Nederlands Genootschap voor Fysiotherapie heeft de term 'subacromiale pijn' opgenomen in zijn richtlijn. ${ }^{8,9} \mathrm{Bij}$ een herziening van de NHG-Standaard kan deze classificatie worden overgenomen.

\section{CONCLUSIE}

Dit onderzoek laat zien dat bij patiënten met een eerste episode van subacromiale schouderpijn een behandeling die gebaseerd is op een echografische diagnose de prognose na één jaar niet verbetert. Huisartsen kunnen de NHG-Standaard blijven volgen: overweeg alleen een echografie wanneer patiënten ondanks behandeling pijn blijven houden.

\section{LITERATUUR}

1 Winters JC, Van der Windt DAWM, Spinnewijn WEM, De Jongh AC, Van der Heijden GJMG, Buis PAJ, et al. NHG-Standaard Schouderklachten. Huisarts Wet 2008;51:555-65.

2 Ottenheijm RP, Van 't Klooster IG, Starmans LM, Vanderdood K, De Bie RA, Dinant GJ, et al. Ultrasound-diagnosed disorders in shoulder patients in daily general practice: a retrospective observational study. BMC Fam Pract 2014;15:115.

3 Ottenheijm RP, Hesselmans NJ, Kemper A, Moser A, De Bie RA, Dinant GJ, et al. GPs' perspectives on the diagnostic work-up in patients with shoulder pain: a qualitative study. J Eval Clin Pract 2014;20:239-45.

4 Ottenheijm RPG, Jansen MJ, Staal JB, Van den Bruel A, Weijers RE, De Bie RA, et al. Accuracy of diagnostic ultrasound in patients with suspected subacromial disorders: a systematic review and meta-analysis. Arch Phys Med Rehabil 2010;91:1616-25.

5 Ottenheijm RP, Cals JW, Weijers R, Vanderdood K, De Bie RA, Dinant GJ. Ultrasound imaging for tailored treatment of patients with acute shoulder pain. Ann Fam Med 2015;13:53-5.

6 Ottenheijm RP, Joore MA, Walenkamp GH, Weijers RE, Winkens B, Cals JW, et al. The Maastricht Ultrasound Shoulder pain Trial (MUST): ultrasound imaging as a diagnostic triage tool to improve management of patients with non-chronic shoulder pain in primary care. BMC Musculoskelet Disord 2011;12:154.

7 CHBB. Kaderhuisarts Bewegingapparaat. www.chbb-register_kaderhuis arts_bewegingsapparaat_2012-1_1_0.pdf.

8 Nederlandse Orthopaedische Vereniging. Richtlijn diagnostiek en behandeling van het subacromiaal pijnsyndroom.'s-Hertogenbosch: Neder landse Ortopaedische Vereniging; 2012; www.orthopeden.org.

9 Jansen MJ, Brooijmans F, Geraets JJXR, Lenssen AF, Ottenheijm RPG, Penning LIF, et al. KNGF Evidence statement Subacromiale klachten. Ned Tijdschr Fysiother 2011;121:supplement. 